\title{
Role of Yoga based stress management program towards leadership development in managers
}

\author{
*Padmavati Maharana ${ }^{1}$, Dr Sanjib Patra ${ }^{2}$, Dr. T M Srinivasan ${ }^{3,}$ \\ Dr. H R Nagendra ${ }^{4}$ \\ ${ }^{I}$ (PhD Research Scholar, Dept. of Yoga \& Management, S-VYYASA University, Bangalore, India) \\ ${ }^{2}$ (Assistant Professor, Dept. of Yoga \& Life Sciences, S-VYYASA University, Bangalore, India) \\ ${ }^{3}$ (Dean, Dept. of Yoga \& Physical Sciences, S-VYYASA University, Bangalore, India) \\ ${ }^{4}$ (Chancellor, S-VYYASA University, Bangalore, India)
}

\begin{abstract}
Billions are spent in the west as well as in the east for leadership programs. The question also arises what kind of strategic interventions are really effective. Till date a specific model is not available to answer the above queries. With this back ground, the present study aims to find out how far the Yoga intervention has brought transformation in leaders. A five day Self Management of Excessive Tension (SMET) program, based on the five layer model espoused by yoga theory and is believed to facilitate improvements in qualities required in leadership development. Multi-factor Leadership Questionnaire (MLQ) was used for assessment of 62 managers on Oil and Natural Gas Corporation. A significant improvement $(p<0.05)$ in the attributes of the managers is observed in the pre-post results. This empirical study can be a solution and could introduce a new paradigm in the field of leadership development.
\end{abstract}

Keywords : IYM, Leadership development, MLQ, SMET, Yoga,

\section{INTRODUCTION}

The transformation from a manager to an effective leader is quite possible, though difficult [1]. Transformational leadership is hence, the most effective of all types and widely acceptable. A Transformational leader engages others in such a way that the leaders and followers help each other to rise to higher levels of motivation and morality [2]. Transformational leadership consists of four components: charisma or idealized influence, inspirational motivation, intellectual stimulation, and individualized consideration [3]. It can foster the emergence of socially desirable behaviors in employees. When it is combined with Karma-Yoga (working without expecting fruits), it might enhance these desirable behaviors further leading to better 'job involvement' [4]. Karma yoga is positively correlated to transformational leadership, effectiveness, extra effort, and satisfaction [5]. A manager emerges as a transformational leader with his loyalty, social values and self less behavior [6].

A longitudinal study looked at the impact of a two-day leadership- training program on transformational leadership in a large manufacturing organization in eastern India. The study demonstrated that leadership training programs in an unplanned way does not produce desirable results [7]. There are about six types of conventional leadership intervention viz., leadership training, role-play, scenario, assignments \& expectations etc. and all of them could produce positive impact on work outcomes in terms of effectiveness. Considering the overall results, there is only $34 \%$ chance of success cases of the existing leadership development programs [8].

Further, there are no studies conducted thus far to understand the impact of yoga on leadership and also there is no model for all round development, ranging from physical to intellectual and spiritual qualities of managers. With this background the current study is aimed to throw light on the possible role of Integrated Yoga Module for Transformational leadership in particular and total leadership in general.

\section{Materials And Methods}

A sample size of sixty two subjects was recruited for the current study and their age was ranging from 35 to 60 years (mean age 52.52 \pm 5.04 ). All subjects were undergoing a Self Management of Excessive Tension workshop (SMET) at Swami Vivekananda Yoga Anusandhana Samsthana University, Bangalore, Karnataka of South India and all of them were deputed of Oil and Natural Gas Corporation Limited (ONGC), India. The criteria that were set to include subjects for the present study were top level executives having at least 25 years of work experience of both genders, having no prior exposure to yoga, willingness to participate and those who reported to the physician regarding their distress due to work pressure. The present study consisted of senior 
managers with an average of 27 years of work experience (Mean \pm SD; 27.02 \pm 5.46 years) in ONGC. Further those women during pregnancy [9], self-reported individuals with serious life-style disorders, metabolic, endocrine and psychiatric disorders, sleep disorders and subjects consuming alcohol were excluded. The present study was approved by Institutional Ethics Committee and a written consent was obtained from all subjects after explaining them about the trial.

\subsection{Study design and assessment}

All subjects were assessed on Day 1 and on Day 6. A multifactor leadership Questionnaire (MLQ) was administered and the objective behind assessing this questionnaire was to explore the nine leadership factors and three leadership outcomes. The MLQ has been used extensively during the past 20 years and is valid and reliable across cultures and types of organizations. A variety of studies have shown the MLQ to be effective in settings as diverse as savings banks, community action agencies, offshore oil platforms, the United States Army, Chinese state-run industry, and the Israel Defense Force infantry[10].The detail description of the tool is mentioned below.

\subsection{Multi factor leadership Questionnaire}

This tool assessed the previously indicated nine leadership factors viz., idealized influence (attributed Idealized Influence (Attributed) (IIA), Idealized Influence (Behavior) (IIB), Inspirational Motivation(IM), Intellectual Stimulation (IS), Individual Consideration(IC), Contingent Reward (CR), Management-byException (Active)(MBE-A), Management-by-Exception (Passive) (MBE-P), Laissez-faire Leadership (LL) and three leadership outcomes: extra effort (EE), effectiveness (EFF), and satisfaction (SAT). Inter correlations of .80 to .90 have been reported using the MLQ 5X with different scales representing each of these factors [11].

The MLQ Leader Form 5x-Short is a 45-items questionnaire that attempts to determine the multiple factors constituting a person's leadership styles and uses a 5-point Likert-type scale (0-4) indicating the frequency of use of each of the 12 areas being measured. The MLQ comprises of a self and multi-rater questionnaire which can be completed online and contains forty-five elements.

\subsection{Intervention Model}

As mentioned earlier, it is thought that for over all external and internal spiritual developments, SMET based yoga theory is ideal for holistic leadership development. As a part of SMET, series of theory lectures and practice sessions were introduced for all subjects based on the concept of Pancha kosha derived from Taitriya Upanishad .According to this Upanishad our body is made up of 'Panca Kosa'(five layers of human existence), named Annamaya Kosa(Physical layer), Pranamaya Kosa (vital energy layer), Manomaya Kosa (mental layer), Vijnanamaya Kosa (intellectual layer) and Anandamaya Kosa (happiness/blissful layer) [12]. Detailed explanation about theory and practice sessions is quoted in TABLE 1 and 2.

\subsection{Data extraction and analysis}

The study consisted of administering MLQ to managers before and after intervention. The scores were derived by summing the items of MLQ and dividing by the number of items that make up the scale. All of the leadership style scales had four items, Extra Effort had three, Effectiveness had four, and Satisfaction had two items. The scale was a 5 point Likert scale ranging from 0-4. Score '0' representing 'Not at all' and '4' representing 'Frequently' if not 'Always'. Data were analyzed using 'R-Studio' statistical software and paired sampled ' $t$ ' test was used to analyze the Pre and Post comparison of the intervention.

\subsection{Results}

Pre and post comparison of the intervention using paired sampled ' $\mathrm{t}$ ' test suggested that II-A $(\mathrm{p}<0.05)$, IS ( $\mathrm{p}<0.001)$ and IC $(\mathrm{p}<0.05)$ components of MLQ were higher following the intervention model of five days. It was also noticed that there was no change in the other components of MLQ following the same and total score was found to be higher $(\mathrm{p}<0.05)$ which is statistically significant. Detailed information about the result is quoted in TABLE 3.

TABLE 1: THEORY SESSIONS CONDUCTED DURING SMET

\begin{tabular}{|l|l|l|}
\hline Day & Session 1 & Session 2 \\
\hline 1 & Introduction to SMET & Concept of stress according to modern medical science \& yoga \\
\hline 2 & Recognition is half solution & Stress and its' release \\
\hline 3 & Executive Growth-I (Depth of Perception) & Executive Growth-II (Expansion of Awareness) \\
\hline 4 & Group Dynamics & Research findings of SMET \\
\hline
\end{tabular}


TABLE 2: PRACTICE SESSIONS CONDUCTED DURING SMET

\begin{tabular}{|c|c|c|}
\hline Day & Session 1 & Session 2 \\
\hline 2 & $\begin{array}{ll}\text { a. } & \text { QRT(Quick Relaxation Technique) } \\
\text { b. } & \text { Vajrasana, } \\
\text { c. } & \text { Ardha ustrasana/ustrasana, } \\
\text { d. } & \text { sithila dandasana } \\
& \text { DRT (Deep Relaxation Technique) }\end{array}$ & $\begin{array}{l}\text { Full session: Starting from IRT to DRT including all standing } \\
\text { and sitting postures) with recognition of stimulation and } \\
\text { relaxation. }\end{array}$ \\
\hline 3 & $\begin{array}{l}\text { Full session: Allowing the relaxation more than } \\
\text { stimulation }\end{array}$ & $\begin{array}{l}\text { Full session: Experiencing the blood flow, blood pressure, } \\
\text { synchronization of pulse, heartbeat and nerve impulses }\end{array}$ \\
\hline 4 & $\begin{array}{l}\text { Full session: Experiencing the changes in emotions and } \\
\text { thoughts with pointed, linear, surface and three } \\
\text { dimensional awareness of the whole body }\end{array}$ & $\begin{array}{l}\text { Full session: Enjoying the group awareness expanding to all- } \\
\text { pervasive awareness. }\end{array}$ \\
\hline
\end{tabular}

TABLE 3: RESULTS OF MLQ PRE-POST SCORES

\begin{tabular}{|c|c|c|c|c|c|c|c|c|}
\hline $\begin{array}{c}\text { Sl. } \\
\text { No. }\end{array}$ & $\begin{array}{c}\text { Variables } \\
\text { Studied }\end{array}$ & $\begin{array}{c}\text { Pre } \\
\text { Mean } \pm \text { SD }\end{array}$ & $\begin{array}{c}\text { Post } \\
\text { Mean } \pm \text { SD }\end{array}$ & $\begin{array}{c}\text { \% } \\
\text { Change }\end{array}$ & $\begin{array}{c}\text { Confidence } \\
\text { Interval }\end{array}$ & $\begin{array}{c}\text { T- } \\
\text { Value }\end{array}$ & ES & P-Value \\
\hline 1 & II-A & $3.16 \pm 0.56$ & $3.07 \pm 0.61$ & $5.70 \%$ & -0.35 to -0.01 & -2.17 & -3.6 & $0.03^{*}$ \\
\hline 2 & II-B & $3.10 \pm 0.51$ & $3.12 \pm 0.63$ & $5.16 \%$ & -0.20 to 0.17 & .16 & -0.13 & 0.86 \\
\hline 3 & IM & $3.16 \pm 0.56$ & $3.27 \pm 0.67$ & $3.48 \%$ & -0.28 to 0.06 & -1.3 & -1.01 & 0.19 \\
\hline 4 & IS & $2.85 \pm 0.58$ & $3.14 \pm 0.64$ & $10.18 \%$ & -0.43 to -0.14 & -4.10 & -4.83 & $0.00^{* * *}$ \\
\hline 5 & IC & $2.72 \pm 0.65$ & $2.96 \pm 0.68$ & $8.46 \%$ & -0.45 to -0.01 & -2.15 & -7.66 & $0.03 *$ \\
\hline 6 & CR & $3.06 \pm 0.50$ & $3.18 \pm 0.61$ & $3.59 \%$ & -0.27 to 0.04 & -1.50 & -1.05 & 0.14 \\
\hline 7 & MBE-A & $2.68 \pm 0.80$ & $2.70 \pm 0.90$ & $0.75 \%$ & -0.21 to 0.17 & -0.20 & -0.2 & 0.83 \\
\hline 8 & MBE-P & $2.81 \pm 0.57$ & $2.83 \pm 0.67$ & $0.71 \%$ & -0.18 to 0.14 & -0.23 & -0.2 & 0.81 \\
\hline 9 & LFL & $3.23 \pm 0.78$ & $3.29 \pm 0.78$ & $1.86 \%$ & -0.26 to 0.13 & -0.68 & -0.68 & 0.49 \\
\hline 10 & EE & $2.87 \pm 0.68$ & $2.92 \pm 0.82$ & $1.74 \%$ & -0.27 to 0.16 & -0.48 & -0.37 & 0.62 \\
\hline 11 & EFF & $3.07 \pm 0.62$ & $3.21 \pm 0.70$ & $4.23 \%$ & -0.32 to 0.05 & -1.4 & -1.66 & 0.16 \\
\hline 12 & SAT & $3.25 \pm 0.60$ & $3.35 \pm 0.70$ & $4 \%$ & -0.29 to 0.08 & -1.10 & -1.04 & 0.27 \\
\hline 13 & Total & $35.39 \pm 4.24$ & $37.05 \pm 5.61$ & $3.81 \%$ & -2.64 to -0.06 & -2.1 & 0.4 & $0.03 *$ \\
\hline
\end{tabular}

*The variables are explained under Materials and Methods.

${ }^{* * *} \mathrm{p}<0.001,{ }^{*} \mathrm{p}<0.05$, comparing the pre and post of intervention model using paired sampled ' $\mathrm{t}$ ' test

\section{Discussions}

Recapitulating the findings, significant improvements in idealized influence (attributed), intellectual stimulation and individualized consideration were observed. However, overall finding of leadership development was found significant following the SMET intervention model. To measure the results effectively, we assessed MLQ and post hoc power analysis was carried out with G power software. It was demonstrated that the study achieved effect size of 0.4 and power of 0.98 . The objective of the present study was to see the effect of intensive intervention module on transformational leadership development and the above mentioned findings satisfy the objectives to an extent.

Similar observation was also noticed in the previous studies. In the previous findings, it was observed that there was significant change in inspirational motivation by $8.28 \%$, management by exception by $43.22 \%$, effectiveness by $8.66 \%$, attributed and satisfaction by $28.57 \%$ [13]. However, in the current study, change that was observed in idealized influence-attributed by $6.01 \%$, intellectual stimulation by $10.17 \%$, individualized consideration by $8.46 \%$ and overall leadership development by $3.81 \%$.Improvements were noticed in the earlier study was quite different from the current findings. In a similar type of interventional study two days of leadership development with 6 months of follow-up showed improvement in eight domains of MLQ such as idealized influence-behavior, inspirational motivation, intellectual stimulation, individualized consideration, contingent reward, and active management-by- exception [14]. Although significant improvement in many domains was noticed in the previous studies compared to the current study but individualized influence (attributed) was found to be significant only in the present study. An improvement in the five layers of the pancha kosha level indicates overall physical, mental and spiritual aspects of the person. It is believed that leadership should contain all these attributes in a leader. As seen in this study three parameters named II-A, IS and IC, have improved significantly. The intellectual and spiritual aspect of improvement is IS. The increase of the parameter II-A is related to overall attitude which is in manomaya kosha. The pancha kosha are interlinked and hence increase in one would contribute to other kosha as well. 
Transformational leadership characteristics are found to have significant relationship with job satisfaction. Among these characteristics, individualized consideration is found to be contributed most in job satisfaction [15]. Managers practicing Karma-Yoga can adopt Transformational Leadership style [16] easily. Spiritual intelligence is the back bone of any system to come up and exist in corporate life [17]. Previous finding suggest that Transformational leadership is correlated with emotional quotient \& emotional intelligence [18] and personality traits (Guna) [19].

Discussing the impact of SMET as a part of integrated yoga module for corporate, it has been demonstrated that SMET could improve the emotional stability [20] and emotional intelligence [21,22] and in corporate top line managers (leaders). Apart from these findings, it has been well documented through previous psycho-physiological research carried out in our research laboratories suggest that Cyclic meditation, which is a key component of SMET could produce positive impact on attention [23], slow wave sleep (quality of sleep) [24] in healthy volunteers and physiological stress [25] in corporate leaders. Yoga has already been considered an effective intervention found to reduce the anxiety [26] and stress [27] and as stress reduces the leadership abilities by increasing the amount of diurnal cortisol [28]. Hence SMET would have produced a noticeable change in the MLQ scores of the leaders.

\section{CONCLUSION AND FUTURE IMPLICATIONS}

This study was first of its kind in which a trend was noticed in MLQ scores suggestive of better leadership development through SMET intervention. An organization always looks for a leader who could elevate the team member to the height of all achievements. Therefore wide range of leadership development programs were emerged for making a complete leader. Unfortunately the conventional programs seldom give outcome in the leaders due to lack of practical approach. A five days SMET intervention with an insight of group dynamics \& executive growth along with the practices could bring about significant trend in MLQ scores which suggests that SMET as part of Yoga could be an effective tool for managing stress and hence enhancing managerial leadership. These findings have implication in both government and private bodies aspiring for leadership in their organizations and the intervention programs need to be tested in every organization using better measurement tools with more rigorous controlled designs. There can be a follow up for all leaders to understand the sustaining leadership qualities, behaviors and styles in an organization. Undoubtedly an organization set up can be more suitable to address the stress in leadership, change in behavior and health benefits in general.

\section{Acknowledgements}

We are very thankful to ONGC managers who participated voluntarily in this trial. We sincerely thank Vivekananda Yoga Anushandhanam Samsthanam in organizing this workshop for managers. Our gratitude to Mr. Pratap Chandra Sarangi, Dr. Balaram Pradhan, Mr. Rabindra Mohan Acharya, Dr. Judu Ilavarasu, Mr. Kuldeep Kushwah and Dr. T Indira Rao for their consistent assistance and inspiration.

\section{REFERENCE}

[1] R. G. Ahangar, Building managers as transformational leaders in public sector Banks, International Review of Business Research Papers, 5(5), 2009, 355-364.

[2] J. M. Burns, Leadership (New York, NY: Harper and Row Publishers, 1978).

[3] B. M. Bass, Leadership and performance beyond expectations. New York: Free Press, 1985.

[4] S. Elankumaran, Personality, organizational climate and job involvement: An empirical study. Journal of Human Values, 10(2), 2004, 117-130..

[5] A. Menon, V. R. Krishnan, Transformational leadership and follower's Karma-yoga: role of follower's gender.Journal of Indian Psychology, 22(2), 2004, 50.

[6] N. Singh, and V. R. Krishnan, Towards understanding transformational leadership in India. Journal of Business Persepectives, 19(2), 200502.

[7] V. R. Krishnan, Training programs on leadership: do they really makes a difference? In Proceedings of the Seminar on 'Role of HR: A New Agenda', IIT Delhli, India, 2000(September), 1-9.

[8] R. J. Reichard, and B. J. Avolio, Where are we? The status of leadership Intervention research: A meta-analytic summary. Authentic leadership and practice: Origins, effects, and development, 2005, 203-26.

[9] V. Kakkar, D. Kaur, K. Chopra, A. Kaur, and I. P. Kaur, Assessment of the variation in menopausal symptoms with age, education and working/non-working status in north-Indian sub population using menopause rating scale (MRS). Maturitas, 57(3), 2007, 306314.

[10] B. J. Avolio and B. M. Bass, Multifactor leadership questionnaire. Mgkind Garden, Menlo Park, CA, 2004.

[11] B. M. Bass, and B. J. Avolio, Transformational leadership: A response to critiques. In M.M. Chemmers \& R. Ayman (Eds), Leadership theory and research: Perspectives and directions, SanDiego, CA: Academic Press, 1993, 49-88.

[12] R. Nagarathna and H. R. Nagendra, Yoga for promotion of Positive Health. Bangalore, India: Swami Vivekananda Yoga Prakashana,2008.

[13] G. Cunningham, \& A. Kitson, An evaluation of the RCN clinical leadership development programme: part 2. Nursing Standard, 15(13), 2000, 34-40.

[14] V. R. Krishnan, Training programs on leadership: do they really makes a difference? In Proceedings of the Seminar on 'Role of HR: A New Agenda', IIT Delhli, India, 2000, 1-9. 
[15] C. S. Long, W. M. M. Yusof, T. O. Kowang, and L. H. Heng, The Impact of Transformational Leadership Style on Job Satisfaction. World Applied Sciences Journal, 29(1), 2004, 117-124.

[16] B. Satpathy, (2011).Transformational Management and Karma-Yoga Linkage. Sri Lankan Journal of Human Resource Management, 1(2), 2011,1-11.

[17] S. Sharma, and A. Prasad, Need for spiritual intelligence to strengthen Leadership, team culture, employee branding and ethical conduct at each level of hierarchy. Asian Journal of Business and Economics, 3(3.3), 2013, 1-16.

[18] A. K. Raina, and N. K. Sharma, The Relationship among Emotional intelligence,Transformational Leadership and Effectiveness: An Empirical Assessment of Entrepreneurs in Rajasthan. European Journal of Business and Management, 5(6), 2013, 59-68.

[19] V. R. Krishnan, Impact of Transformational Leadership and Karma-Yoga on Organizational Citizenship Behavior, 9(1), 2005 , 1-17.

[20] S. Kumari, N. C. B. Nath, and H. R. Nagendra, Enhancing emotional competence among managers through SMET. Psychological studies-university of calicut, 52(2), 2007, 171.

[21] H. Adhia, Nagendra, H. R., \& B. Mahadevan, Impact of adoption of yoga way of life on the emotional intelligence of managers. IIMB Management Review, 22(1), 2010, 32-41.

[22] T. S. Ganpat, and H. R. Nagendra, Yoga therapy for developing emotional intelligence in mid-life managers. Journal of mid-life health, 2(1), 2011, 28.

[23] P.Sarang and S. Telles, Effects of two yoga based relaxation techniques on heart rate variability (HRV).International Journal of Stress Management, 13(4), 2006, 460.

[24] S. Patra, and S. Telles, (2010).Heart rate variability during sleep following the practice of cyclic meditation and supine rest. Applied psychophysiology and biofeedback, 35(2), 2010, 135-140.

[25] R. P. Vempati, and S. Telles, Baseline occupational stress levels and physiological responses to a two day stress management program. J Indian Psychol, 18(1-2),2000, 33-37.

[26] D. Lakkireddy, D. Atkins, J. Pillarisetti, K. Ryschon, S. Bommana, J. Drisko, and B. Dawn, (2013). Effect of Yoga on Arrhythmia Burden, Anxiety, Depression, and Quality of Life in Paroxysmal Atrial Fibrillation ,the YOGA My Heart Study. Journal of the American College of Cardiology, 61(11), 2013, 1177-1182.

[27] K. Yoshihara, T. Hiramoto, T. Oka, C. Kubo, and N. Sudo, Effect of 12 weeks of yoga training on the somatization, psychological symptoms, and stress-related biomarkers of healthy women. BioPsychoSocial medicine, 8(1), 2014, 1-9.

[28] G. D. Sherman, J. J. Lee, A. J. C. Cuddy, J. Renshon, C. Oveis, J. J. Gross, and J. S. Lerner, Leadership is associated with lower levels of stress.Proceedings of the National Academy of Sciences of the United States of America, 109(44), 2012, 17903-7. doi:10.1073/pnas.1207042109. 